ISSN: 2146-3042

DOI: $10.25095 /$ mufad.673717

\title{
Finansal Kriz Ortamlarında Sermaye Yapısının Bankaların Finansal Performanslarına Etkileri*
}

\begin{tabular}{|c|c|}
\hline & $\begin{array}{l}\text { Bener GÜNGÖR }{ }^{* *} \\
\text { Murat DİLMAÇ*** }\end{array}$ \\
\hline $\begin{array}{l}\text { ÖZET } \\
\text { Bu çalışmada } 2008 \text { küresel krizin ülkemizde etkisinin belirgin bir ş } \\
\text { sektöründe faaliyet gösteren ticari bankaların finansal performansları } \\
\text { incelenmiştir. Çalışmanın amacı, kriz ortamlarında bankaların sermaye } \\
\text { üzerindeki etkilerini tespit etmektir. Bu kapsamda Türk bankacılık sekt } \\
\text { bankasının 2002:4-2015:1 yılları arasındaki çeyrek dönemlere ait verile } \\
\text { edilmiş̧tir. Yapılan analizlerden Türkiye'deki bankaların performansla } \\
\text { özkaynak ve daha fazla uzun vadeli yabancı kaynak, mevduat ve mevduat } \\
\text { faydalı olacağı sonucu elde edilmiştir. Ayrıca 2008 küresel finans krizir } \\
\text { pozitif yönde etkilediği tespit edilmiştir. } \\
\text { Anahtar Kelimeler: Sermaye Yapısı, Bankalar, Panel Veri Analizi } \\
\text { JEL Sınıflandırması: G32, G21, C23 }\end{array}$ & $\begin{array}{l}\text { diği dönemde bankacılık } \\
\text { apıları arasındaki ilişki } \\
\text { finansal performansları } \\
\text { et gösteren } 12 \text { mevduat } \\
\text { analiz yöntemiyle analiz } \\
\text { neleri için daha düşük } \\
\text { ile çalışmalarının daha } \\
\text { f finansal performansını }\end{array}$ \\
\hline
\end{tabular}

\section{Effects Of Capital Structure To Financial Performance Of Banks In Financial Crisis: An Application On The Turkish Banking Sector}

\section{ABSTRACT}

In this study the relation between financial performance and capital structure of commercial banks in the period of which operating in the influence of 2008 global crisis is felt deeply has been analysed. The aim of this study is to determine the effect of banks capital structure on their financial performance in the crisis environment. In this context, quarterly data belonging to the period 2002:4-2015:1 of 12 deposit banks operating in Turkish banking sector are analyzed by using Stata program and panel data method. Empirical results of the study show that equity / total liabilities ratio has negatively affect more than other capital structure ratios and it would be helpful to use less equity and more long term liabilities, deposits and non-deposit liabilities in order to increase the performance of deposit banks in Turkey. On the other hand, the global financial crisis which hit the world in 2008 has a positive relationship with financial performance of Turkish commercial banks.

Keywords: Capital Structure, Banks, Panel Data Analysis.

Jel Classification: G32, G21, C23

* Bu makale Atatürk Üniversitesi Sosyal Bilimler Enstitüsünde yürütülen “Finansal Kriz Ortamlarında Sermaye Yapısının Bankaların Finansal Performanslarına Etkileri: Türk Bankacılık Sektörü Üzerine Bir Uygulama" başlıklı doktora çalışmasının bir özetidir.

Makale Gönderim Tarihi: 21.02.2019, Makale Kabul Tarihi: 07.06.2019, Makale Türü: Araştırma Makalesi

** Prof. Dr., Atatürk Üniversitesi, İktisadi İdari ve Bilimler Fakültesi, bgungor@atauni.edu.tr, ORCID:00000002-0523-3810.

*** Dr. Öğr. Üyesi, Atatürk Üniversitesi, Beşeri ve Sosyal Bilimler Fakültesi, mdilmac@atauni.edu.tr, ORCID: 0000-0002-2842-9875. 


\section{GíRiş}

Kısa aralıklarla 2000 Kasım ve 2001 Şubat tarihlerinde Türkiye'de yaşanan krizler, bankacılık sektörünün ülke ekonomisi için önemini unutulmayacak bir biçimde tecrübe ettirmiştir. Krizlerden çıkarılan dersler doğrultusunda 2000 ve 2001 krizleri sonrası bankacılık sektöründe gerçekleştirilen yeniden yapılandırma ve devamında denetim ve düzenleme mekanizmalarının sıkı bir şekilde uygulanması sektörün sağlıklı bir yapıya kavuşmasını ve istikrarlı bir şekilde büyüme sürecine girmesini sağlamıştır.

2000'li yılların başından 2007 yılı ortalarına kadar dünya ekonomisinde, yüksek büyüme rakamlarının ve likidite bolluğunun olduğu bir dönem yaşanmıştır. $\mathrm{Bu}$ dönemde Türkiye ekonomisi de istikrarlı bir şekilde yüksek büyüme rakamlarına ulaşmıştır. Bunda hem dünya ekonomik konjonktürünün hem de yıllar sonra gelen tek başına bir iktidarın getirdiği istikrar ve finansal piyasalara güven ortamının sağlanmasının etkisinin olduğu da söylenebilir. Ancak 2007'de ABD'de geri ödeme gücü zayıf kredi geçmişi olumsuz olan kişilere verilen mortgage kredilerinin geri ödenmemesi ile başlayan, kısa sürede tüm dünyayı da etkisi altına alan küresel ekonomik kriz bu dönemin de sonunu getirmiştir.

2008 küresel krizi gelişmiş ve gelişmekte olan ekonomiler başta olmak üzere tüm dünya ekonomisini etkisi altına almış, bu durumdan ülkemiz de etkilenmiştir. Ancak küresel kriz ülkemizde reel sektörü şiddetli bir şekilde etkilerken, bankacılık sektörünü aynı şekilde etkilemediği hatta bu dönemde bankacılık sektörünün reel sektörden daha az etkilendiği görülmüştür. Kriz döneminde Türkiye ekonomisinin büyüme, işsizlik oranları, kapasite kullanım oranı ve sanayi üretim endeksi gibi reel kesim göstergeleri hızla bozulmasına karşılık bankacılık sektöründe finansal sağlamlık, sermaye yapısı, karlılık, kredi büyüme hızı, mevduat büyüme hızı, aktif büyüme hızı ve istihdam gibi önemli göstergelerde ciddi bir bozulma yaşanmamıştır.

Firmaların karlılı̆̆ını, değerini ve finansal performansını etkileyen önemli unsurlardan biri olarak görülen sermaye yapısının bankalar için önemi büyüktür. Bankaların ana faaliyet konusu parasal işlemler ve bu işlemlere aracılık yapmak olduğundan dolayı güçlü ve etkin bir sermaye yapısına ihtiyaç duymaktadırlar. Bankacılıkta sermayenin en önemli işlevi, üstlenilen risklerden kaynaklanabilecek muhtemel veya çok yüksek miktarlı beklenmeyen zararları karşılamaktır. Bu bakımdan çalışmada Türk bankacılık sektöründe faaliyet gösteren bankaların küresel kriz döneminde göstermiş oldukları finansal performansın sermaye yapısı ile ilgisi incelenmeye çalışılmıştır. Bunu gerçekleştirmek için bankaların uzun vadeli kaynakları olarak sayılan bir yıldan uzun vadeli mevduatlar, uzun vadeli krediler ve özkaynaklardan oluşan sermaye yapısı ile finansal performansın arasındaki ilişki ele alınmıştır. Çalışma sermaye yapısı değişkeninin içeriği ve kapsadığı dönem itibarıyla diğer çalışmalardan ayrılmaktadır.

Çalışmada Türk bankacılık sektöründe faaliyet gösteren ve sektörün toplam aktif büyüklüğü içindeki payı \%87 olan 12 mevduat bankasının 2002:4 - 2015:1 arasında üçer aylık dönemlerinin bilanço ve gelir tabloları incelenmiştir. Çalışmada öncelikle konu ile ilgili yapılmış ampirik literatüre incelenmiş, ardından çalışmada kullanılan değişkenlerin ve yöntemin ele alındığı veri seti ve yöntem kısmına geçilmiştir. Çalışmanın dördüncü bölümünde ise regresyon analiz sonuçları verilmiş ve son olarak elde edilen bulguların genel bir değerlendirilmesi yapılmıştır. 


\section{LITERATÜR}

Finansal performans ve sermaye yapısı üzerine aktiflerin karlılığı (Return of Assets ,ROA), özkaynak karlılığı (Return of Equity, ROE) ve net faiz marjı (Net Interest Margin, NIM) kullanılarak yapılmış birçok yurt içi ve yurtdışı çalışma bulunmaktadır. Yapılan literatür taraması sonucunda bu çalı̧̧malardan araştırmamıza konu, kapsam ve metodoloji bakımından benzerliği bulunan çalışmalar ele alınmış ve elde edilen bulgularla beraber kronolojik bir şekilde aşăğıda sunulmuştur.

Athanasoglou vd. (2006), 1998-2002 dönemleri arası Güneydoğu Avrupa'daki bankalar üzerinde yaptıkları çalışmalarındabankaların güçlü sermayeleri sayesinde mali sıkıntıların maliyetlerini azaltabileceği ve daha iyi bir performans beklentisini makul bir biçimde arttırabileceği bulgusunu elde etmişlerdir. Hoffmann (2011), 1995-2007 yilları arasında ABD bankaları üzerinde yaptığı çalışmasında, yüksek sermaye rasyosunun düşük karlılığa sebep olduğunu tespit etmiştir. Hoffman çalışmasında ayrıca düşük karlılığa bağlı olarak bankaların sermaye oranı ile öz sermaye karlılığı arasında negatif bir ilişki tespit etmiş̧ir. Hoffmann bunun bir nedeni olarak bankaların likiditasyon, temerrüt riski, finansal sıkıntılara karşı bankaların kısmen korunmak için karlılı̆̆1 gözard1 ederek daha düşük sermaye oranlarını seçtiklerini öne sürmüş̧ür.

Taşkın (2011), 1995-2009 döneminde faaliyet gösteren Türk bankacılık sektöründeki ticari bankalara ait performansları etkileyen içsel ve dışsal faktörleri belirlemeyi amaçlamıştır. Taşkın, bankacılık performansının daha çok mikro değişkenlerden etkilendiği ve makroekonomik faktörlerin istatistiki olarak anlamlı düzeyde bir etkisinin olmadığını bulmuştur. 2001 krizinin genel olarak negatif etkisinin olması da ekonominin genel olarak istikrarlı durumda olmasının banka performansını etkilediğini göstermektedir. Macit (2012), 2005:1.-2010:4. dönemleri arasında Türkiye'de faaliyet gösteren katılım bankalarına ait karlılı̆ı etkileyen makroekonomik belirleyicileri incelemiştir.Macit, "Özkaynak/Toplam Aktiflerin" aktiflerin karlılı̆̆na pozitif, sermayenin karlılı̆ına negatif bir etkisi bulunduğunu tespit etmiştir. İskenderoğlu vd. (2012), ticari bankalarda büyüklüğün, büyümenin ve sermaye yapısı kararlarının karlılığa olan etkisini analiz etmek için yaptıkları çalışmada, bankaların karlılığının kalıcı olduğunu, sermaye yapısı kararlarına ilişkin oranların bankaların karlılığı üzerinde negatif bir etkisi olduğunu ancak büyüklüğün ve büyüme oranının karlılık üzerinde pozitif bir etkiye sahip olduğunu göstermiş̧tir.

Saeed vd. (2013), Karaçi borsasında işlem gören bankaların 2007 - 2011 yılları arasındaki verilerini kullanarak bankaların sermaye yapısının performans üzerine etkilerini incelemek için yaptıkları çalışmada,uzun vadeli yabancı kaynaklar ile performans ölçütleri arasında negatif, kısa vadeli yabancı kaynaklar ve toplam borç oranı ile performans ölçütleri arasında pozitif bir ilişki tespit etmişlerdir

Amba ve Almukharreq (2013), 27 İslami, 65 geleneksel bankanın 2006 - 2009 dönemine ait verileri kullanarak küresel krizin bu bankaların karlılık (Aktif Karlılı̆̆ı-ROA, Özkaynak Karlılı̆ı-ROE, Net Faiz Marj1-NIM), sermaye yapısı (Özkaynak / Toplam Aktifler), likidite ve yükümlülükleri üzerine etkilerini T-testini kullanarak incelemişlerdir. Araştırmacıların çalışmada amaçladıkları, İslami bankacılığın geleneksel bankacılıktan farklı olarak krizlere karşı koyabilen ve güçlü yapıları olduğu iddialarını test etmektir. Amba ve Almukharreq'e ait araştırma bulgularına göre, finansal krizin her iki banka grubuna ait 
karlılık göstergelerinde negatif etkisi olduğunu, özkaynakrasyosunun hem İslami bankalarda hem de geleneksel bankalarda azaldığını bulmuşlardır. Bunun yanında geleneksel bankaların maddi özkaynaklar/toplam borçlar rasyosunun artmasına karşılık İslami bankacılığın maddi özkaynaklar/toplam borçlar rasyosunun azaldığını tespit etmişlerdir.

Göçmen vd. (2013 ), küresel krizin Türk bankacıllk sektörü üzerinde etkilerini incelemek için 2002:4-2012:3 arasındaki 41 çeyrek dönemini kapsayan, yerli ve yabanc1 bankalarla karşılaştırmalı bir analiz yapmışlardır. Araştırmanın bulgularına göre kriz döneminde vergi öncesi aktif karlılığının normal dönemden yüksek olduğu, bir diğer ifade ile küresel krizin Türk bankacılık sektörü üzerinde pozitif etki yaptığını tespit etmişlerdir. Bu durumu Z-skoru'ndan elde edilen sonuçların da desteklediği bulunmuştur. Z-skoru ile elde edilen bulgulara göre kriz dönemlerinde bankalar iflastan daha uzak olduğu tespit edilmiştir.

Ayaydın ve Karakaya (2014), Türk bankacılık sektöründeki 23 banka üzerinde 20032011 dönemini kapsayan çalışmalarında, net faiz marjının aktif karlılığı ve özkaynak karlılıkları arasında negatif yönlü bir ilişki, aktif karlılığı ve özkaynak karlılıkları arasında ise pozitif yönlü bir ilişki olduğunu bulmuşlardır. Ayrıca, araştırma kapsamındaki tüm bankaların özkaynak karlılı̆̆ ile sermayesi arasında negatif yönde bir ilişki olduğu ve yabancı sahipliği ile performans oranları arasında negatif bir ilişki olduğu tespit edilmiştir.(Samırkaş vd., 2014), Ocak 2003-Haziran 2012 dönemleri arasında Türkiye'de faaliyet gösteren mevduat bankalarının karlılığı üzerinde etkiye sahip faktörleri belirlemek için yaptıkları çalışmada, aktif karlılığının ve özkaynak karlılığının, faiz dışı gelirlerin aktif toplamına oranından ve özkaynak / toplam aktif oranından pozitif yönde etkilendiği bulgusu elde edilmiştir.

Literatürde sermaye yapısı ve finansal performans ile ilgili yapılmış olan ampirik analizlerin, seçilmiş bir özeti Tablo 1'de sunulmuştur. Tablo 1, literatürde kullanılan bağımlı değişkenler aktif karlılığı (ROA), özkaynak karlılığı (ROE) ve net faiz marjı (NIM) ile istatistiki olarak anlamlı bulunan bağımsız değişkenlerin ilişkilerinin bir özetini göstermektedir.

Tablo 1. Sermaye Yapısı Ve Finansal Performans İlişkisi Üzerine Yapılmış Çalışmalar

\begin{tabular}{|c|c|c|c|}
\hline $\begin{array}{l}\text { Bağımlı } \\
\text { Değişken }\end{array}$ & Bağımsız Değişkenler & $\begin{array}{l}\text { Pozitif yönlü istatistiki } \\
\text { olarak anlamlı ilişki }\end{array}$ & $\begin{array}{l}\text { Negatif yönlü } \\
\text { istatistiki olarak } \\
\text { anlamlı ilişki }\end{array}$ \\
\hline \multirow{7}{*}{$\begin{array}{c}\text { ROA } \\
\text { (Aktif } \\
\text { Karlılığ } 1)\end{array}$} & Özkaynak/Toplam Aktif (Pasif) & $\begin{array}{l}\text { Abreu ve Mendes (2001), } \\
\text { Kaya (2002), Athanasoglou } \\
\text { vd (2006), Atasoy (2007) } \\
\text { Demirhan (2010), Macit } \\
\text { (2012), Samırkaş (2014) }\end{array}$ & Turgutlu (2014) \\
\hline & Toplam Borçlar/Öz Sermaye & Şahin (2011) & $\begin{array}{l}\text { Zeitun ve Tian } \\
(2007)\end{array}$ \\
\hline & Toplam Mevduatlar/Toplam Aktif (Pasif) & $\begin{array}{l}\text { Kaya (2002), Demirhan } \\
\text { (2010), }\end{array}$ & \\
\hline & Toplam Borç/ Toplam Aktif (Pasif) & & $\begin{array}{l}\text { Kabakçı (2007), } \\
\text { Zeitun ve Tian } \\
(2007)\end{array}$ \\
\hline & Uzun Vadeli Borçlar/Toplam Aktif(Pasif) & Zeitun ve Tian (2007) & \\
\hline & Uzun Vadeli Borçlar/Toplam Borçlar & & Şahin (2011) \\
\hline & Kriz & & Taşkın (2011) \\
\hline
\end{tabular}




\begin{tabular}{|c|c|c|c|}
\hline & Z Skoru & Turgutlu (2014) & \\
\hline \multirow{8}{*}{$\begin{array}{c}\text { ROE } \\
\text { (Özkaynak } \\
\text { Karlılığı) }\end{array}$} & Özkaynak/Toplam Aktif (Pasif) & $\begin{array}{l}\text { Abreu ve Mendes (2001), } \\
\text { Kaya (2002), Athanasoglou } \\
\text { vd (2006), Demirhan } \\
\text { (2010), Samırkaş (2014), } \\
\text { Turgutlu (2014) }\end{array}$ & $\begin{array}{l}\text { Hoffman (2011), } \\
\text { Taşkın (2011), } \\
\text { Macit (2012), } \\
\text { Ayaydın-Karakaya } \\
\text { (2014) } \\
\end{array}$ \\
\hline & Toplam Borçlar/Öz Sermaye & & $\begin{array}{c}\text { Kabakçı (2007), } \\
\text { Kabakçı (2008) }\end{array}$ \\
\hline & Toplam Mevduatlar/Toplam Aktif (Pasif) & Demirhan (2010) & $\begin{array}{c}\text { Kaya (2002), } \\
\text { Hoffman (2011), } \\
\text { İskenderoğlu vd. } \\
\text { (2012) }\end{array}$ \\
\hline & Toplam Borç/ Toplam Aktif (Pasif) & & $\begin{array}{c}\text { Abor }(2005), \\
\text { Ayaydın-Karakaya } \\
(2014) \\
\end{array}$ \\
\hline & Uzun Vadeli Borçlar/Toplam Aktif(Pasif) & & $\begin{array}{c}\text { Abor (2005), } \\
\text { Kabakçı (2007), } \\
\text { Kabakç1 (2008) }\end{array}$ \\
\hline & Uzun Vadeli Borçlar/Toplam Borçlar & & \\
\hline & Kriz & Taşkın (2011) & \\
\hline & Z Skoru & Turgutlu (2014) & \\
\hline \multirow{8}{*}{$\begin{array}{l}\text { NIM } \\
\text { (Net Faiz } \\
\text { Marj1) }\end{array}$} & Özkaynak/Toplam Aktif (Pasif) & $\begin{array}{c}\text { Abreu ve Mendes (2001), } \\
\text { Kaya (2002), Atasoy } \\
\text { (2007) Demirhan (2010) }\end{array}$ & $\begin{array}{l}\text { Abreu ve Mendes } \\
(2001) \text {, Ayaydın- } \\
\text { Karakaya (2014) }\end{array}$ \\
\hline & Toplam Borçlar/Öz Sermaye & & \\
\hline & Toplam Mevduatlar/Toplam Aktif (Pasif) & Demirhan (2010) & Kaya (2002), \\
\hline & Toplam Borç/ Toplam Aktif (Pasif) & & $\begin{array}{c}\text { Ayaydın-Karakaya } \\
(2014)\end{array}$ \\
\hline & Uzun Vadeli Borçlar/Toplam Aktif(Pasif) & & \\
\hline & Uzun Vadeli Borçlar/Toplam Borçlar & & \\
\hline & Kriz & $\begin{array}{l}\text { Abreu ve Mendes (2001), } \\
\text { Kaya (2001), Taşkın (2011) }\end{array}$ & \\
\hline & Z Skoru & & \\
\hline
\end{tabular}

\section{METODOLOJi}

İşletmeden işletmeye farklılık göstermekle birlikte sermaye yapısı işletme performansını yakından ilgilendirmektedir. Sermaye yapısı ve bileşimi birçok işletme için önem arz etmekle beraber banka işletmeleri için ayrı bir öneme sahiptir. Banka işletmelerinin faaliyet konuları gereği kaynak yapılarının büyük çoğunluğu yabancı kaynaklardan oluşmaktadır. $\mathrm{Bu}$ kaynaklar başka türdeki işletmeler için bankalar kadar çok çeşitli ve alternatif maliyete sahip değildir.

Bankaların ihtiyaç duydukları fonların temininde kullanılan kaynakların vade yapısının uzun vadeli kaynakların lehine ağırlıklı olması halinde karlılıklarının artacağı öngörülmektedir. Ancak bunun yanında kaldıraç düzeyinde veya bir başka ifadeyle borç oranındaki aşırı bir artış bankaların kaynak maliyetinin yükselmesine sebep olacaktır.Böyle bir durumda ise banka karlılığında düşüş gözlemlenecektir.

Küresel krizin Türkiye ekonomisi üzerinde etkisini hissettirdiği dönemde bankaların diğer sektörlerden farklı olarak krizden daha az etkilendiği veya etkilenmediği algısı 
oluşmuştur. Bunun temelinde 2001 krizi sonrası gerçekleştirilen reformlar ve sonrasında sektörün oldukça sıkı bir şekilde denetim ve kontrol altında tutulması görüşü genel kabul görmektedir.

Araştırmanın temel amacı küresel krizin ülkemizde etkili olduğu dönemde Türk bankacılık sektöründe faaliyet gösteren mevduat bankalarının sermaye yapısı ile finansal performansları arasındaki ilişkiyi incelemektir. Bu amaçla Türk bankacılık sektöründe faaliyet gösteren ve sektörün toplam aktif büyüklügü içindeki payı \%87 olan 12 mevduat bankasının 2002:4 - 2015:1 arasında üçer aylık dönemlerinin bilanço ve gelir tabloları incelenmiştir.

Çalışmada kullanılan veri setleri hem zaman hem de yatay kesit boyutuna sahip verilerden oluşmaktadır. $\mathrm{Bu}$ duruma bağlı olarak uygun modelleme ve tahminleme yapabilmek için panel veri regresyon analizi tekniği tercih edilmiştir. Bankaların finansal performans ölçümünde kullanılan aktif karlılığı, özkaynak karlılığı ve net faiz marjının bağımlı değişken olarak kullanılmasına karar verilmiştir. Sermaye yapısını temsil etmek için seçilen özkaynak oranı, toplam uzun vadeli yabancı kaynaklar oranı, mevduat oranı ve mevduat dışı kaynaklar oranı ise bağımsız değişkenleri temsil etmektedir. Çalışmada kriz dönemleri 2008:3-2009:3 dönemlerini kapsayan ve veri setinde 1 ile temsil edilen kukla değişken kullanılmıştır. Kontrol değişkeni olarak ise $\mathrm{Z}$ skoru değişkeni kullanılmıştır.

Analizde öncelikle her üç model için yatay kesit bağımlılığı test edilmiş, ardından her bir veri setine durağanlık testleri uygulanmıştır. Sonraki aşamada klasik, sabit etkiler ve tesadüfi etkiler modellerinin geçerlilikleri test edilmiş ve modellerle ilgili varsayımlardan sapmalar olup olmadığı tespit etmek için otokorelasyon ve değişen varyans testleri yapılmıştır. Son olarak her üç model için uygun tahminciler belirlenmiş ve model tahmin sonuçları elde edilmiştir.

\section{VERİ SETİ}

Çalışmada, Türk bankacılık sektöründe faaliyet gösteren, çalışmanın kapsadığı dönem içerisinde uzun vadeli yabancı kaynak verileri düzenli olan 27 mevduat bankasından 12 'si ele alınmıştır. Çalışmada kullanılan veriler, 2002:4-2015:1 arası dönemi kapsayan, Türkiye Bankalar Birliği resmi internet sitesinde yayınlanan bankaların finansal raporlarından elde edilmiştir. Çalışmada kullanılan uzun vadeli yabancı kaynak verilerinin Türkiye Bankalar Birliği resmi internet sitesinde sunulmaya başlandığ 1 2002:4 dönemi başlangıç olarak kabul edilmiştir ve finansal verileri kullanılan bankaların listesi Tablo 2'de sunulmuştur.

Tablo 2. Analize Dahil Edilen Bankalar

\begin{tabular}{|ll|ll|}
\hline 1 & Türkiye Cumhuriyeti Ziraat Bankası A.Ş. & 7 & Türkiye Garanti Bankası A.Ş. \\
2 & Türkiye Halk Bankası A.Ş. & 8 & Türkiye İş Bankası A.Ş. \\
3 & Türkiye Vakıflar Bankası T.A.O. & 9 & Yapı ve Kredi Bankası A.Ş. \\
4 & Akbank T.A.Ş. & 10 & Denizbank A.Ş. \\
5 & Şekerbank T.A.Ş. & 11 & Finans Bank A.Ş. \\
6 & Türk Ekonomi Bankası A.Ş. & 12 & HSBC Bank A.Ş. \\
\hline
\end{tabular}




\subsection{Modeller ve Değişkenler}

Çalışmada literatürde sıklıkla kullanılan ve muhasebe tabanlı performans ölçüm araçları olan aktif karlılığı (ROA), özkaynak karlılığı (ROE) ve net faiz marjı (NIM) bağımlı değişkenler olarak seçilmiştir.

ROA bir şirketin toplam aktiflere bağlı olarak ne kadar karlı olduğunu ölçmektedir. İşletmeler aktiflerini kaynaklar ile finanse etmektedirler. Bankalar açısından bakıldığında, kullanılan kaynak ve vade çeşitliliğinin tercihinde doğru seçim yapılması ve kaynak maliyetinin düşürülmesi, başta mevduat olmak üzere aktiflerden elde edilen getirinin de karlılığını arttıracaktır. ROE işletme sermayesine yatırılan her bir birim kaynağın getirisini yüzde olarak hesaplamaktadır. NIM bankaların aracılık fonksiyonunun gelir yaratma kapasitesini, aracılık işlemlerinin maliyetini bir başka ifade ile bankanın etkinliğini ölçer.

Sermaye yapısını belirlemede literatürde çeşitli oranlar kullanılmaktadır. Çalışmada sermaye yapısını incelemek için Tablo 4.1.1.'de verilen oranlar kullanılmıştır.

OZK, özkaynakların toplam kaynak yapısı içindeki payını göstermektedir. Özkaynakların toplam aktif içindeki payının yüksek olması vergi kalkanını azaltarak işletmenin karlılığına negatif yönde etki edebilir. UVYK, uzun vadeli yabancı kaynakların toplam pasif içindeki payını göstermektedir. Bankaların uzun vadeli yabancı kaynakları 1 yıl veya daha uzun vadeli olan mevduatlar, birikimli mevduat, ihraç edilen menkul kıymetler ve uzun vadeli sendikasyon kredilerinin toplamından oluşmaktadır. Özkaynak ve diğer kısa vadeli yabancı kaynakların aksine maliyetlerinin daha düşük olması ve banka aktif pasif yapısında vade uyumuna olumlu etkisi sebebi ile karlılığa pozitif yönde etki etmesi beklenebilir. TUV değişkeni ise, özkaynakların ve uzun vadeli yabancı kaynakların toplamının pasiflere bölünmesi ile elde edilmektedir. UVOZ, uzun vadeli yabancı kaynakların özkaynaklara bölünmesi ile elde edilen bir orandır. Varlık yapısının finansmanında kullanılan uzun vadeli borç-özkaynak ilişkisini incelemekte kullanılmaktadır. Bu değişkendeki yüksek oranlar riskli bir durumu ifade etmekle beraber, kaldıraç etkisi ile banka karlılığını pozitif yönde etkileyebilir.

MVD değişkeni, bankaların kaynak yapısının önemli bir bileşeni olan mevduatların toplam aktiflere oranını ifade etmektedir. Faiz oranları, vade yapısı ve işletme giderlerine (şubeleşme ve mevduat toplama faaliyetleri gibi) bağlı olarak banka karlılığını olumsuz yönde etkileyebilmektedir. MDK değişkeni banka kaynak yapısındaki mevduatın haricindeki yabancı kaynakların pasif toplamına oranını ifade etmektedir. MDK alınan krediler, para piyasalarına borçlar, diğer yabancı kaynaklar, ihraç edilen menkul kıymetler (net) ve sermaye benzeri kredilerin toplamından oluşmaktadır.

Kontrol değişkeni olarak kullanılan ZSKORU (Z-score), bankaların finansal sağlamlığının bir göstergesi olarak kabul edilmektedir. Z skoru bankanın borcunu ödeyememe riskine olan uzaklığ 1 ifade etmektedir ve eğer bu skor yüksek ise gelişmiş bir riske uyarlanmış performans1, düşük ise iflas riskini işaret etmektedir (Turgutlu, 2014, 46). Çalışmada bankalara ait Z skoru verilerinin doğal logaritması (LnZ) alınarak analize dahil edilmiştir.

Bankaların finansal performansları üzerindeki etkisini kontrol etmek amacı ile kriz için KRIZ şeklinde ifade edilen kukla değişken kullanılmıştır. KRIZ değişkeni, 2008 küresel 
ekonomik krizinin Türkiye ekonomisi ve bankacılık sektörü üzerinde etkin olduğu 2008:3 2009:3 dönemi dikkate alınarak belirlenmiştir ve krizin etkili olduğu bu döneme 1 değeri, diğer dönemlere ise 0 değeri verilmiştir.

Tablo 3. Çalışmada Kullanılan Değişkenler

\begin{tabular}{|c|c|}
\hline Bağımlı Değişkenler & $\begin{array}{r}\text { Açıklama } \\
\end{array}$ \\
\hline ROA & Aktif Karlılığg = Dönem Net Karı / Toplam Aktifler \\
\hline ROE & Özkaynak Karlılığ $=$ Dönem Net Karı / Özkaynaklar \\
\hline NIM & Net Faiz Marj1 = Net Faiz Gelirleri / Toplam Aktifler \\
\hline \multicolumn{2}{|c|}{ Bağımsız Değişkenler } \\
\hline OZK & Özkaynaklar / Toplam Pasif \\
\hline UVYK & Uzun Vadeli Yabancı Kaynaklar / Toplam Pasif \\
\hline TUV & Toplam Uzun Vadeli Kaynaklar / Toplam Pasif \\
\hline UVOZ & Uzun Vadeli Yabancı Kaynaklar / Özkaynaklar \\
\hline LnZ & $\mathrm{LN}\left(\mathrm{Z}\right.$ Skoru $\left.=\frac{\mathrm{ROA}+\frac{\text { Ozkaynalklar }}{\text { Toplam.Aktî }}}{\sigma \mathrm{ROA}}\right)$ \\
\hline MVD & Toplam Mevduat / Toplam Pasif \\
\hline MDK & Toplam Mevduat Dışı Kaynaklar / Toplam Pasif \\
\hline KRIZ & Kriz kukla değişkeni. 2008:3 - 2009:3 dönemi için 1, diğer dönemler için 0 . \\
\hline
\end{tabular}

Çalışmada, Türk bankacılık sektöründe faaliyet gösteren ticari bankaların sermaye yapısının 2008 küresel kriz döneminde finansal performanslarını nasıl etkilediğini tespit edebilmek amaciyla, banka finansal performansinı temsilen kullanılan ve Tablo 3'de sunulan bağımlı değişkenlerden ROA, ROE ve NIM değişkenlerinin her biri için üç ayrı model oluşturulmuştur ve bu modellere ilişkin bilgiler 1, 2 ve 3 numaralı denklemlerde sunulmuştur.

MODEL 1: $\quad R O A=\beta_{0}+\beta_{1} O T P_{i t}+\beta_{2} T U T P_{i t}+\beta_{3} U V O z_{i t}+\beta_{4} M V D_{i t}+\beta_{5} M D K_{i t}+\beta_{6} L n Z_{i t}+\beta_{7} K R I Z_{i t}+\varepsilon_{i t}$

MODEL 2: $\quad R O E=\beta_{0}+\beta_{1} O T P_{i t}+\beta_{2} T U T P_{i t}+\beta_{3} U V O Z_{i t}+\beta_{4} M V D_{i t}+\beta_{5} M D K_{i t}+\beta_{6} L n Z_{i t}+\beta_{7} K R I Z_{i t}+\varepsilon_{i t}$

MODEL 3: $\quad N I M=\beta_{0}+\beta_{1} O T P_{i t}+\beta_{2} T U T P_{i t}+\beta_{9} U V O z_{i t}+\beta_{4} M V D_{i t}+\beta_{5} M D K_{i t}+\beta_{i} L n Z_{i t}+\beta_{7} K R I Z_{i t}+\varepsilon_{i t}$

Burada MODEL 1 aktif karlılığı (ROA) modelini, MODEL 2 özkaynak karlılığ (ROE) modelini ve MODEL 3 net faiz marjı (NIM) modelini temsil etmektedir.

\subsection{Panel Veri Analizi}

Bilimsel araştırmalarda birçok farklı veri türünden yararlanılmaktadır. Bu veri türleri yapılarına ve yapılan analiz amaçlarına uygun olan istatistiki modellerle incelenebilmektedir. Firmaların mali tablolarından elde edilen veriler ile zaman serisi ve yatay dikey kesit verileri ile ayrı ayrı analizler yapılabilmekle beraber bu kesit verileri birleştirerek panel veri analizi de yapilabilmektedir.

Panel veri analizi, zaman boyutuna sahip kesit serilerini kullanarak ekonomik ilişkilerin tahmin edilmesi yöntemi olarak bilinmektedir. Panel veri analizinde zaman serileri ile kesit serileri bir araya getirilerek hem zaman hem de kesit boyutuna sahip bir veri seti oluşturulmaktadır. Günümüzde birçok çalışmada zaman ve yatay kesit verilerinin birleştirilmesi yolu ile elde edilen veri setleri oluşturulmaya başlanmıştır (Pazarlıoğlu ve Gürler, 2007: 37). 
Genel olarak panel veri modeli aşağıdaki gibi ifade edilmektedir.

$$
Y_{i t}=\alpha_{i t}+\beta_{k i t} X_{k i t}+\varepsilon_{i t} \quad i=1, \ldots, N ; t=1, \ldots, T
$$

burada, Y: bağımlı değişkeni, $X_{k}$ : bağımsız değişkenleri, $\alpha$ sabit parametreyi, $\beta$ eğim parametrelerini ve u hata terimini ifade etmektedir. $i$ alt indisi birey, firma, ülke gibi birimleri ifade ederken, $\mathrm{t}$ alt indisi ise gün, ay veya yıl olarak zamanı ifade etmektedir. Değişkenlerin, parametrelerin ve hata teriminin i ve $t$ alt indisini taşıması, panel veri setine sahip olduklarını göstermektedir. Bu modelde sabit ve eğim parametreleri hem birimlere hem de zamana göre değer almaktadır (Tatoğlu, 2012: 4).

(4) numaralı denklem ile ifade edilen modelde, katsayılar her bir birim için farklı zaman periyotlarında farklı değerleri göstermektedir. Böyle bir durumda tahmin edilen parametre sayısının kullanılan gözlem sayısını aşması söz konusudur. Bir diğer ifade ile model tahmin edilememektedir.

Bu dezavantaj yüzünden panel veri ile yapılan çalışmalarda daha çok hata terimlerinin özellikleri ve katsayıların değişebilirliği ile ilgili farklı varsayımlarda bulunarak farklı modeller elde edilebilmektedir. Farklı varsayımlarla oluşturulan modeller Sabit Etkili Model ve Tesadüfi Etkili Model olarak adlandırılmaktadır. Her iki modelde de, $e_{i t}$ hatalarının tüm zaman dönemlerinde ve tüm bireyler için bağımsız ve $\mathrm{N}\left(0, \sigma_{\Theta}^{2}\right)$ şeklinde dağıldığ varsayılmaktadır. (Pazarlıoğlu ve Gürler, 2007: 37).

\subsection{Analiz Test Sonuçları}

Panel veri modellerinde, hangi modelin geçerli olabileceğini saptamada çeşitli testler kullanılmaktadır. Bunlar; klasik modelin geçerliliğini test etmede kullanılan F testi, Klasik model ile tesadüfi etkiler modelini test etmede kullanılan LR olabilirlik oranı testi ve sabit etkiler modeli ile tesadüfi etkiler modelini test etmede kullanılan Hausman testidir.

Ekonometrik analizlerde kullanılan serilerin durağan özellikler taşıması çok önemlidir. Durağan olmayan serilerle yapılan analizler sahte (superious) tahmin sonuçları vermektedir (Kaya, 2014: 297). Bütün zaman serileri analizinde olduğu gibi, hem zaman hem de yatay kesit analizini bir arada gerçekleştiren panel veri analizlerinde de değişkenler arasında sahte ilişkilere neden olunmaması için değişkenlerin durağan olması gerekmektedir(Korkmaz vd., 2010: 100).

Durağanlık, birim kök testi ile araştırılır. Panel birim kök testleri de iki guruba ayrılmaktadır. Birinci kuşak testler, birimler arasında korelasyon olmadığını varsaymaktadır. Korelasyon varsa bu testlerin gücü zayıftır. İkinci kuşak panel birim kök testlerinin temel özelliği ise, birimlere ait seriler arasında korelasyon olduğunu varsaymaktadır(Korkmaz ve Karaca, 2013: 173).

Birim kökün varlığını test etmek için öncelikle yatay kesit bağımlılığının test edilmesi gerekmektedir. Panel veri setinde yatay kesit bağımlılı̆̆ı reddedilirse 1 . nesil birim kök testleri, aksi durumda 2. nesil birim kök testlerini kullanmak daha tutarlı, etkin ve güçlü 
tahminleme yapılmasını mümkün kılmaktadır (Çınar, 2010: 594). Panel veri analizlerinin temel varsayımlarından biri olan yatay kesit bağımlılığının olmaması varsayımı test edilmiştir. Birimler arası korelasyonsuzluk varsayımı testi için Pesaran CD Testi kullanılmıştır. Pesaran Testi sonuçları tablo 4.3.1.'de sunulmuştur.

Tablo 4. Pesaran Yatay Kesit Bağımlılı̆g (Cross-sectionDependence) Testi

\begin{tabular}{lcc}
\hline Model & Pesaran CD Test İstatistiği & Olasılık (P) \\
\hline MODEL 1 & 27.931 & 0.000 \\
MODEL2 & 25.482 & 0.000 \\
MODEL 3 & 42.611 & 0.000 \\
\hline
\end{tabular}

Tablo 4.3.1 de gösterilen Pesaran (2007) Testi sonuçlarına göre, "yatay kesit bağımlılığ1 yoktur" biçiminde ifade edilen $\mathrm{H}_{0}$ hipotezi \%1 önem düzeyinde reddedilmiştir ( $\mathrm{P}$ $=0.0000<\alpha=0.01$ ). Bir diğer ifadeyle, her üç modelde de yatay kesit bağımlılı̆̆ının var olduğu sonucuna varılmıştır.

Yatay kesit bağımlılığının varlığı nedeniyle çalışmanın bu kısmında ele alınan değişkenler ikinci nesil birim kök testi olan Pesaran (2007) testi ile durağanlığın varlığ araştırılacaktır. İlk olarak değişkenlerin seviyelerinde durağan olup olmadıkları incelenmiş ve elde edilen bulgular Tablo 5'de sunulmuştur.

Tablo 5. Pesaran Birim Kök Testi ile Durağanlığın Düzeyde I(0) Araştırılması

\begin{tabular}{|c|c|c|c|c|}
\hline \multirow[b]{2}{*}{ Değişkenler } & \multirow{2}{*}{$\begin{array}{l}\text { Sabit terimli } \\
\text { Z İstatistiği }\end{array}$} & \multicolumn{3}{|c|}{ Sabit terimli ve trendli } \\
\hline & & Olasılık (P) & Z İstatistiği & Olasılık (P) \\
\hline ROA & -9.286 & 0.000 & -9.024 & 0.000 \\
\hline ROE & -9.078 & 0.000 & -8.892 & 0.000 \\
\hline NIM & -6.865 & 0.000 & -5.879 & 0.001 \\
\hline OZK & -8.192 & 0.000 & -8.182 & 0.000 \\
\hline TUV & -4.997 & 0.000 & -3.857 & 0.000 \\
\hline UVOZ & -2.257 & 0.012 & -1.425 & 0.077 \\
\hline MVD & -4.894 & 0.000 & -3.950 & 0.000 \\
\hline MDK & -5.509 & 0.000 & -4.301 & 0.000 \\
\hline LnZ & -5.408 & 0.000 & -5.229 & 0.000 \\
\hline
\end{tabular}

Tablo 5'den elde edilen ampirik sonuçlar tüm değişkenler için $\mathrm{H}_{0}$ hipotezinin reddedildiğini yani $\% 10, \% 5$ ve $\% 1$ önem seviyelerinde söz konusu serilerin durağan olduğunu göstermektedir.

Değişkenlerin durağan olup olmadığının araştırılmasının ardından çalışmanın sonraki aşamasındaher üç model için klasik modelin geçerliliği F testi kullanılmıştır. F testi panel veri modellerinde klasik modelin geçerliliğini sabit etkiler modeline karşı test etmek için kullanılmaktadır. F testi verilerin birimlere göre farklılık göstermediğini, birim ve/veya zaman 
etkilerinin olup olmadığını test etmektedir. F testi tüm birim etkilerinin sıfıra eşit olduğu hipotezi $\left(\mathrm{H}_{0}: \mu_{\mathrm{i}}=0\right)$ sinamaktadır (Tatoğlu, 2012: 164). Panel veri analizine konu olan üç panel regresyon modeli için yapılan F testi sonuçları Tablo 6 'da sunulmuştur.

Tablo 6. F Testi Sonuçları

\begin{tabular}{lcc}
\hline Model & F istatistiği & Olasilık (P) \\
\hline MODEL 1 & 139.93 & 0.0000 \\
MODEL2 & 104.09 & 0.0000 \\
MODEL 3 & 22.59 & 0.0000 \\
\hline
\end{tabular}

Çalışmada kullanılacak olan üç model için yapılan F Testi sonucunda hesaplanan F test istatistiklerini gösteren Tablo 4.3.4.'e göre, MODEL 1, MODEL 2 ve MODEL 3 için $\mathrm{H}_{0}$ hipotezi reddedildiğinden sabit etkilere karşı klasik modelin geçerli olmadığı belirlenmiştir.

Klasik modeli tesadüfi etkiler modeline karşı test etmek için kullanılan Olabilirlik oranı (LR) testi, Klasik model doğrudur şeklinde kurulan $\mathrm{H}_{0}$ hipotezini q (kısıt sayısı) serbestlik derecesi ile $\chi^{2}$ dağılan LR testi ile test edilmektedir. $\mathrm{H}_{0}$ reddedilirse birim ve/veya zaman etkilerinin olduğuna karar verilir. Birim etkilerin standart hatalarının sıfıra eşit olduğu; diğer bir ifade ile klasik modelin uygun olduğu temel hipotezi $\left(\mathrm{H}_{0}: \sigma_{\mu}=0\right)$ sinanmaktadır. LR test istatistiği hesaplanırken, klasik model ve tesadüfi etkiler modeli en çok olabilirlik yöntemi ile tahmin edilmekte ve her ikisinden elde edilen log-olabilirlik değerleri kullanılmaktadır (Tatoğlu, 2012: 168).

Tablo 7. Olabilirlik Oranı Test Sonuçları

\begin{tabular}{lcrr}
\hline & \multicolumn{2}{c}{ Olabilirlik Oranı Test İstatistiği } \\
\hline Test Türü & \multicolumn{1}{c}{ Model 1 } & \multicolumn{1}{c}{ Model 2 } & \multicolumn{1}{c}{ Model 3 } \\
\hline Birim Etkisi & $666.56^{* * *}$ & $546.36^{* * *}$ & $132.65^{* * *}$ \\
Zaman Etkisi & $109.72^{* * *}$ & $50.87^{* * *}$ & $491.55^{* * *}$ \\
Birim ve Zaman Etkilerinin Testi & $666.68^{* * *}$ & $546.56^{* * *}$ & $774.30^{* * *}$ \\
\hline$* * *$
\end{tabular}

${ }^{*},{ }^{* *}$ ve ${ }^{* * *}$ surasıyla $0.10,0.05$ ve 0.01 düzeyinde istatistiksel olarak anlamlılığ ifade etmektedir.

Tablo 7'de MODEL 1, MODEL 2 ve MODEL 3 için yapılmış birim ve zaman etkilerinin testi, birim etkilerinin testi ve zaman etkilerinin testlerinin sonuçlarını göstermektedir. Olabilirlik oranı test sonucuna göre MODEL 1, MODEL 2 ve MODEL 3 için $\mathrm{H}_{0}$ hipotezi, birim ve zaman etkilerinin varlığ $1 \% 1$ önem düzeyi için reddedilmiştir. Yani MODEL 1,MODEL 2 ve MODEL 3 için klasik modelin geçerli olmadığ1 anlaşılmaktadır. Dolayısıylaher üç modelde de birim, zaman ve birim ve zaman etkilerinin var olduğu ve klasik modelin uygun olmadığı belirlenmiştir.

Hausman Testi, modellerin tahmininde tesadüfi etkiler veya sabit etkili modellerinden hangisinin seçileceği hususunda bilgi sunar. Bu nedenle tüm modellere Hausman testi uygulanmıştır. Elde edilen sonuçlar Tablo 8'de sunulmuştur. 
Tablo 8. Hausman Testi Sonuçları

\begin{tabular}{lcc}
\hline Model & Hausman Test İstatistiği & Olasilık (P) \\
\hline MODEL 1 & 3788.02 & 0.0000 \\
MODEL 2 & 1372.36 & 0.0000 \\
MODEL 3 & 85.18 & 0.0000 \\
\hline
\end{tabular}

Tablo 8'e göre, MODEL 1, MODEL 2 ve MODEL 3 için " $H_{0:}$ Tesadüfi etkiler tahmincisi doğrudur" hipotezi reddedildiğinden sabit etkiler tahmincisinin tutarlı olduğu belirlenmiştir.

Panel veri analizinin önemli varsayımlarından olan, bağımsız değişkenler arasında ilişkinin olmaması varsayımını test etmek amacıyla, modeller için belirlenen sabit etkiler modellerinde otokorelasyonun varlığını sinamak amacıyla, Bhargava, Franzini ve Narendranathan tarafindan önerilen Durbin-Watson testi gerçekleştirilmiştir. Her üç model için tespit edilen Durbin-Watson Testi sonuçları Tablo 9'da verilmiştir.

Tablo 9. Durbin-Watson ve Baltagi-WuLBI Test Sonuçları

\begin{tabular}{lcc}
\hline Model & Durbin-Watson Test İstatistiği & Baltagi-Wu LBI \\
MODEL 1 & 0.7212 & 0.9275 \\
MODEL 2 & 0.7591 & 08694 \\
MODEL 3 & 1.6212 & 1.7841 \\
\hline
\end{tabular}

MODEL 1, MODEL 2 ve MODEL 3 için $d_{600}, 7,0.05$ tablo değerleri $d_{L}$ ve $d_{u}$ için sırasıly 1.8457 ve 1.8861 olarak bulunmuş, bunun sonucunda Durbin-Watson hesap değeri <Durbin-Watson tablo değerleri olduğu için modelde otokorelasyon olduğu sonucuna varılmıştır.

Panel veri analizinde yatay kesit birimler içinde hata süreci homoskedastik iken varyansının birimlere göre değişebildiği durumla karşılaşıllabildiği için, her üç model için değişen varyans test edilmiştir. Değişen varyansı dikkate alan Wald testi kullanılmış ve sonuçlar Tablo 10'da sunulmuştur.

Tablo 10. Değişen Varyans Testi

\begin{tabular}{lcc}
\hline Model & $\chi^{2}$ & Olasillk \\
\hline MODEL 1 & 401.96 & 0.0000 \\
MODEL 2 & 2369.62 & 0.0000 \\
MODEL 3 & 80.67 & 0.0000 \\
\hline
\end{tabular}

Tablo 10'da sunulan Wald Testi sonuçlarına göre sonuçlara göre $\mathrm{H}_{0}$ hipotezi reddedilmekte, varyansın birimlere göre değisstiği anlaşılmakta ve dolayısıyla birimlere göre heteroskedasite olduğu yani her üç modelde de değişen varyans olduğu sonucuna varılmıştır.

Çalışmada, ROA, ROE ve NIM bağımlı değişkenlerini tahmin etmekte kullanılacak her üç modelde de;otokorelasyon, birimler arası korelasyon ve değişen varyans sorunlarının 
bulunmas1 nedeniyle, Stata/SE 12.0 programından yararlanılarak Driscoll-Kraay'in sabit etkiler tahmincisi ile panel veri analizi tahminleri yapılmıştır. Elde edilen sonuçlar Tablo 11 'de sunulmuştur.

Tablo 11.Model 1, Model 2 ve Model 3'e Ait Regresyon Sonuçları

\begin{tabular}{|c|c|c|c|c|}
\hline \multicolumn{2}{|l|}{ Değişkenler } & $\begin{array}{c}\text { Model } 1 \\
\text { (ROA) }\end{array}$ & $\begin{array}{c}\text { Model } 2 \\
\text { (ROE) }\end{array}$ & $\begin{array}{l}\text { Model } 3 \\
\text { (NIM) }\end{array}$ \\
\hline \multicolumn{2}{|c|}{ Sabit Terim ( C ) } & $-0.14 * * *$ & $-1.6668^{* * *}$ & 0.0211 \\
\hline \multicolumn{2}{|l|}{ OZK } & $-0.596 * * *$ & $-5.8447 * * *$ & $-0.3764^{*}$ \\
\hline \multicolumn{2}{|l|}{ TUV } & $-0.1454 * * *$ & $-2.1241 * * *$ & $-0.216^{* * *}$ \\
\hline \multicolumn{2}{|c|}{ UVOZ } & $0.015^{* * *}$ & $0.2168 * * *$ & $0.0236^{*}$ \\
\hline \multicolumn{2}{|c|}{ MVD } & $-0.0293^{*}$ & -0.0917 & $-0.166^{* * *}$ \\
\hline \multicolumn{2}{|l|}{ MDK } & $-0.055 * * *$ & $-0.2914^{*}$ & $-0.2171 * * *$ \\
\hline \multicolumn{2}{|l|}{$\operatorname{LnZ}$} & $0.0968 * * *$ & $1.0192 * * *$ & $0.0818 * * *$ \\
\hline \multicolumn{2}{|c|}{ KRIZ } & $0.0009^{* *}$ & $0.0113^{* *}$ & $0.0061 * *$ \\
\hline \multicolumn{2}{|c|}{ Toplam Gözlem } & \multicolumn{3}{|c|}{600} \\
\hline \multicolumn{2}{|c|}{ Banka Sayısı } & \multicolumn{3}{|c|}{12} \\
\hline \multicolumn{2}{|c|}{$F(7,49)$} & $66.78 * * *$ & $26.75^{* * *}$ & $15.94 * * *$ \\
\hline \multicolumn{2}{|l|}{$\mathbf{R}^{2}$} & 0.7584 & 0.7056 & 0.2925 \\
\hline \multicolumn{5}{|c|}{$\begin{array}{l}\text { Sermaye yapısını temsil eden değişkenlerin, bankaların finansal performansını temsil } \\
\text { eden değişkenleri üzerindeki etkilerini MODEL 1, MODEL } 2 \text { ve MODEL } 3 \text { için Tablo } 12 \text { 'de } \\
\text { özetlenmiştir. }\end{array}$} \\
\hline \multicolumn{5}{|c|}{$\begin{array}{c}\text { Tablo 12. Çalışma Kapsamında Bankaların Finansal Performanslarını } \\
\text { Etkileyen Faktörler }\end{array}$} \\
\hline \multirow{2}{*}{ Modeller } & & \multicolumn{3}{|c|}{ İstatistiksel Olarak Anlamlı Değişkenler } \\
\hline & Değişken & Pozitif & \multicolumn{2}{|c|}{ Negatif } \\
\hline MODEL 1 & ROA & $\begin{array}{l}\text { Uzun vadeli yabancı kaynakların } \\
\text { özkaynaklara oranı, Z skoru, Kriz }\end{array}$ & $\begin{array}{r}\text { Özkaynak } \\
\text { kaynakların } 1\end{array}$ & $\begin{array}{l}\text { plam uzun vadeli } \\
\text { oranı, mevduat dışı } \\
\text { klar }\end{array}$ \\
\hline MODEL 2 & ROE & $\begin{array}{l}\text { Uzun vadeli yabancı kaynakların } \\
\text { özkaynaklara oranı, Z skoru, Kriz }\end{array}$ & $\begin{array}{r}\text { Özkaynak } \\
\text { kaynakların }\end{array}$ & $\begin{array}{l}\text { plam uzun vadeli } \\
\text { oranı, mevduat dışı } \\
\text { klar }\end{array}$ \\
\hline MODEL 3 & NIM & $\begin{array}{l}\text { Uzun vadeli yabancı kaynakların } \\
\text { özkaynaklara oranı, Z skoru, Kriz }\end{array}$ & $\begin{array}{r}\text { Özkaynak } \\
\text { kaynakların } 1 \\
\text { kayna }\end{array}$ & $\begin{array}{l}\text { plam uzun vadeli } \\
\text { oranı, mevduat dışı } \\
\text { vduat oranı }\end{array}$ \\
\hline
\end{tabular}


Tablo 12'de ele alınan tüm modellerin tahminlerinin birlikte incelenmesini sağlamaktadır. Modeller içinde bağımsız değişkenlerin bağımlı değişkeni açıklama gücünü gösteren $\mathrm{R}^{2}$ açısından incelediğimizde en güçlü modelin MODEL 1 olduğu görülmektedir.

Özkaynaklar / toplam pasif oranı (OZK) ile aktif karlılı̆̆ 1 (ROA), özkaynak karlılığ1 (ROE) ve net faiz marjı (NIM) arasında negatif ilişki tespit edilmiştir. Elde edilen bu bulgu bankaların yüksek sermaye rasyosuna sahip olmasından veya düşük karlılıktan ortaya çıkmış olmasından kaynaklanmış olması mümkündür. BDDK nın tavsiyesi yönünde bankalar kriz döneminde dönem karlarını ortaklara dağıtmayıp sermayelerine eklemişlerdir. $\mathrm{Bu}$ durum bankaların sermaye oranlarında bir artış meydana getirmiştir. Hofmann (2011) ise bunun bir nedeni olarak bankaların likiditasyon, temerrüt riski, finansal sıkıntılara karşı bankaların kısmen korunmak için karlılığı gözardı ederek daha düşük sermaye oranlarını seçtiklerini öne sürmüştür. Bulgulara göre aktif karlılığı ile olan negatif ilişki Hofmann (2011) ve Taşkın'ın (2014) çalışmaları ile uyumludur. Özkaynak karlılığı ile olan negatif ilişki Ayaydın ve Karakaya'nın (2014), Macit'in (2002),Taşkın'ın (2011), Hofmann'ın (2011) çalışmaları ile uyumludur. Net faiz marjı ile olan negatif ilişki Ayaydın ve Karakaya'nın (2014)ve Hofmann'ın (2011) çalışmaları ile uyumludur. Abreu ve Mendes (2001), Kaya (2002), Athanasoglou vd. (2006), Atasoy (2007) ve Demirhan (2010) bulgularından ise farklilik göstermektedir. Bulgularda benzerlik gösteren çalışmalardan Ayaydın ve Karakaya (2014) ve Taşkın (2014)'da kriz kukla değişkeni kullanılmıştır.

Toplam uzun vadeli kaynakların toplam pasiflere oranını temsil eden TUV değişkeni ise aktif karlılığı, özkaynak karlılığ 1 ve net faiz marjı ile negatif yönlü bir ilişkiye sahiptir. Aktif karlılı̆gı ile negatif yönlü ilişki Zeitun ve Tian'ın (2007) bulguları ile benzerlik göstermektedir. Özkaynak karlılığı ile negatif yönlü ilişki Abor (2005) ve Kabakçı (2008) ile uyumludur. TUV'nin aktif karlılığ1, özkaynak karlılığ 1 ve net faiz marjına olan negatif etkisi özkaynak/toplam pasifler (OZK)ile karşılaştırıldığında daha düşük değerler elde edildiği gözlemlenmektedir.

Uzun vadeli yabancı kaynakların özkaynaklara oranını temsil eden UVOZ değişkeni aktif karlılığg, özkaynak karlılığ1 ve net faiz marjı ile pozitif yönlü bir ilişkiye sahiptir. Bu değişkenden elde edilen verilere göre bankalar kaynak yapısını uzun vadeli yabancı kaynaklar lehine değiştirmekte olduğunu ve bu durumun bankaların finansal performansı üzerinde olumlu bir etkiye sahip olduğunu söyleyebiliriz.

Kriz kukla değişkeninin katsayısı pozitif ve istatistiki olarak anlamlıdır. Yani küresel ekonomik kriz, incelenen bankaların aktif karlılığ1, özkaynak karlılığı ve net faiz marj1 değişkenleri üzerinde istatistiki olarak pozitif ve anlamlı düzeyde etkiye sahiptir. Elde edilen bu bulgu Kaya'nın (2001) ve Taşkın'ın (2011) çalışmalarında elde ettikleri kriz ile net faiz marjı arasındaki pozitif ilişki ile uyumludur. Ayaydın ve Karakaya'nın (2014) ve Taşkın'ın (2011) çalışmalarındaki kriz ile aktif karlılığı arasındaki negatif ilişkisine dair bulgudan Ayaydın ve Karakaya'nın (2014) çalışmalarındaki kriz ile aktif karlılı̆̆ net faiz marjı ile arasındaki negatif ilişkisine dair bulgulardan farklılık göstermiştir.

Bankaların sermaye yapısının bir başka unsuru olan mevduatı temsil eden MVD değişkeni ise aktif karlılı̆̆ı ve net faiz marjı ile negatif yönde bir ilişkiye sahiptir. Kriz dönemlerinde mevduata ait faiz oranlarındaki artış ve mevduatın vade yapısındaki değişim 
bankaların karlılığını olumsuz yönde etkileyebilmektedir. Elde edilen bulgular İskenderoğlu vd. nin (2012) ve Hofmann'ın (2011) çalışmaları ile uyumludur.

Elde edilen bulgulara göre, bankaların sermaye yapısının bir diğer önemli unsuru olan mevduat dışı kaynaklarını temsil eden MDK değişkeni ise aktif karlılığı, özkaynak karlılığı ve net faiz marjı ile negatif yönde bir ilişkiye sahip olduğu tespit edilmiştir. Alınan krediler, para piyasalarına borçlar, ihraç edilen menkul kıymetler ve sermaye benzeri kredilerden oluşan MDK bankaların mevduattan sonra ikinci önemli fon kaynağını oluşturmaktadır. Söz konusu kaynakların banka karlılığı ile olan negatif yönlü ilişkinin kriz dönemi ve sonrasında kaynak maliyetlerinin yani faizlerde yaşanan değişimlerin yanında vade yapısında ve hacminde yaşanan değişikliklerden de kaynaklanmış olabilir.

Çalışmada elde edilen bir diğer bulguya göre, finansal sağlamlık (Z skoru) ile aktif karlılı̆̆ı, özkaynak karlılığı ve net faiz marjı arasında pozitif bir ilişki bulunmaktadır. Bankaların finansal sağlamlığının bir göstergesi olarak kabul edilen Z Skoru ile ilgili bu bulgu Turgutlu'nun (2014) çalışması ile uyumludur. Sermayesi güçlü olan bankaların diğerlerine nazaran daha düşük düzeyde risklilik arz etmektedir(Bozkurt, 2015, 21). Zskoru'nun bağımlı değişkenler ile olan pozitif yönlü ilişkisi de göz önüne alınırsa bankaların karlılığının kriz dönemlerinde sermaye yapılarının riskliliğini azaltabileceğini göstermektedir denilebilir.

\section{SONUÇ}

Ülkemizi 2008 yılından itibaren etkisi altına alan küresel krizin beraberinde getirdiği olumsuzluklar, bankacilık sektörünün hâkim güç olduğu finansal sektörün mü yoksa reel sektörün mü üzerinde daha etkili olduğu görüşü literatürde ve yazılı medyada yoğun tartışmalara sebep olmuştur. Uluslararası piyasalarda talebin daralması ve krizin gelişmiş ülkeleri daha çok etkilemesi, Avrupa Birliğine yönelik ihracat yapan reel sektör başta olmak üzere ekonominin diğer birimleri üzerinde önemli etkileri olduğu bilinmektedir. Satış hacminin daralması, tahsilat sorunları vb. etkenler reel sektörde işsizlik oranlarının artması, kapasite kullanım oranlarının düşmesi ve küçülme gibi önemli sorunları da beraberinde getirmiştir.

Ancak buna karşılık Türk bankacılık sektörü yakın geçmişinde yaşamış olduğu krizler, edinmiş olduğu tecrübeler ve gerçekleştirmiş olduğu yapısal reformların yanında benzerlerine kıyasla çok daha etkin bir düzenleme ve denetim faaliyeti altında ciddi bir önlem alınmasına veya yasal bir düzenleme yapılmasına gerek kalmadan krizden çıkmayı başarmıştır.

Bu çalışmada, Türk bankacılık sektörünün küresel krizin etkin olduğu bir dönemde finansal performansları ile sermaye yapıları arasındaki ilişkinin bir finansal kriz ortamında nasıl bir ilişki sergilediği incelenmeye çalışılmıştır. Bu amaçla sektörün aktif büyüklüğünün yaklaşık \%87 sine sahip olan 12 mevduat bankasının 2002:4 - 2015:1 dönemine ait üçer aylık mali tablolarından elde edilen veriler kullanılmıştır. Araştırmada bankaların finansal performansını ölçmede her ne kadar yeni yöntemler geliştirilse de yurt içi ve yurt dış1 literatürde yoğun bir şekilde kullanılan ve muhasebe tabanlı bir yöntem olan rasyo analizinden faydalanılmıştır.

Uzun vadeli kaynak temini Türk bankacılık sektörünün yıllardan beri yaşadığı önemli bir sorun olarak görülmektedir. 2001 krizi sonrası Türk ekonomisinde sergilenen istikrarlı 
görünüm ile beraber bankacılık sektörü finansal açıdan daha ileriyi görebilme imkânına kavuşmuştur. Kamunun bankalardan borçlanma gereksiniminin azalması ile serbest kalan fonların faizlerinde aşağı yönlü bir seyir söz konusu olmuştur. Ekonomide yaşanan olumlu gelişmeler ile beraber büyüme eğilimine giren reel sektörün artan kaynak ihtiyaçları büyük ölçüde bankacılık sektörünce karşılanmıştır. Türk bankacılık sektörü artan kaynak ihtiyacının önemli bir kısmını mevduatlardan karşılamıştır. Ayrıca, ülke kredi puanlarının olumlu yönde seyri yurt dışı piyasalardan daha ucuz fon kaynağı bulma imkanını ortaya çıkarmıştır.

$\mathrm{Bu}$ çerçeveden bakıldığında, bankaların finansal performansı ile uzun vadeli yabancı kaynaklar arasındaki negatif yönlü ilişkinin özkaynaklarla karşılaştırıldığında daha düşük olan etkisi bankaların karlılığında uzun vadeli yabancı kaynak temininin önemine işaret ettiği söylenebilir. Elde edilen bulgulara göre, bankalar sermaye yapılarını oluştururken özkaynaklardan ziyade uzun vadeli yabancı kaynakları tercih etmeleri halinde finansal performanslarının arttırabilecekleri tahmin edilmektedir. Araştırmadan elde edilen bir diğer bulgu ise bankaların sermaye yapısında ki uzun vadeli yabancı kaynaklarda yaşanan artış ve özkaynaklarda meydana gelen azalış sayesinde bankaların daha düşük düzeyde risklilik gösterdiği ve dolayısı ile krizden daha az etkilendiği görülmüştür.

Sağlam bir yapıya sahip olması gerektiği kadar reel sektörün ihtiyacı olan fon kaynağının da temin edilebilmesi de bankacılık sektörünün etkinliği için önemli bir koşuldur. $\mathrm{Bu}$ çalışmadan elde edilen bulgular ışığında öne çıkan durum, Türk bankacılık sektörünün özkaynak / toplam pasifler oranın yüksekliğine bağlı olarak bankaların finansal performansını önemli derecede negatif yönde etkilenmesidir. Bir başka ifade ile yüksek sermaye oranlarının beraberinde getirdiğgi yükümlülükler bankaların finansal performanslarını düşürmektedir. $\mathrm{Bu}$ sebeple bankaların sermaye yeterlilik oranlarında Basel standartlarının üzerinde uygulanan yasal zorunlulukların yeniden gözden geçirilmesinde fayda bulunmaktadır. Ayrıca son dönemlerde kaynak yapısında azalan bir eğilime ve kısa vade yapısına sahip mevduatların tasarruf sahiplerinin güvenlerinin arttırılması, tasarrufa özendirilmesi veya teşvik edilmesi yolu ile mevduatların kaynak yapısı içindeki vade yapısının uzatılması ve tutar olarak arttırılması bankalar açısından önem arz etmektedir. Böylece bankaların artan kaynak ihtiyacı daha düşük maliyetli fonlarla karşılanırken aynı zamanda ekonomiye aktarılacak düşük maliyetli bu fonlar ekonomik büyümede önemli bir etken olacaktır.

\section{KAYNAKLAR}

Abor, Joshua (2005), "The effect of Capital Structure on Profitability: An Empirical Analysis of Listed Firms in Ghana". The Journal of Risk Finance, pp. 438 - 445. Doi:10.1108/15265940510633505

Abreu, Margarida- Mendes, Victor (2001), "Commercial Bank Interest Margins and Profitability: Evidence From Some EU Countries", Paper Presented at the PanEuropean Conference Jointly Organised by the IEFS-UK \& University of Macedonia Economic \& Social Sciences, Thessaloniki, 17-20 May.

Amba, Muni Sekhar- Almukharreq, Fayza (2013), "Impact of the Financial Crisis on Profitability of the Islamic Banks vs Conventional Banks- Evidence from GCC". International Journal of Financial Research, 4(3), pp. 83-93, Doi:10.5430/ijfr.v4n3p83 
Atasoy, Hakan (2007), Türk Bankacılık Sektöründe Gelir-Gider Analizi ve Karlılık Performansının Belirleyiciler, (Yayımlanmamış Uzmanlık Yeterlilik Tezi ), Ankara: Türkiye Cumhuriyet Merkez Bankası, Bankacılık ve Finansal Kuruluşlar Genel Müdürlüğü .

Athanasoglou, Panayiotis - ManthosDelis - Staikouras, Christos (2006), "Determinants Of Bank Profitability in The South Eastern European Region", Working Paper, No.47. Bank of Greece. (https://ideas.repec.org/p/bog/wpaper/47.html)

Ayaydın, Hasan - Karakaya, Aykut (2014), "The Effect of Bank Capital on Profitability and Risk in Turkish Banking". International Journal of Business and Social Science, 5(1), ss. 252-271 ( http://ijbssnet.com/journals/Vol_5_No_1_January_2014/29.pdf)

Bozkurt, Ayça Topaloğlu (2015), "Bankacılık Sektörü Risk Alma Davranışı ve Para Politikası”. Uzmanlık Yeterlik Tezi, Türkiye Cumhuriyet Merkez Bankası Bankacılık ve Finansal Kuruluşlar Genel Müdürlüğü, Ankara.

Çınar, Serkan (2010), "OECD Ülkelerinde Kişi Başına GSYİH Durağan mı? Panel Veri Analizi", Marmara Üniversitesi İ̈BF Dergisi, 24(2), ss. 591-601. (http://dergipark.gov.tr/muiibd/issue/487/4537)

Demirhan, Dilek (2010), "Türkiye'deki Mevduat Bankalarının Finansal Yapıya İlişkin Kararlarının Karlılık Üzerine Etkileri", Muhasebe ve Finansman Dergisi, (45), ss. 157168( http://journal.mufad.org.tr/attachments/article/166/12.pdf)

Doğan, Mesut (2013, "Sigorta Firmalarının Sermaye Yapısı ile Karlılık Arasındaki İlişki: Türk Sermaye Piyasası Üzerine Bir İnceleme". Muhasebe ve Finansman Dergisi,(57), ss. 121-136 (http://journal.mufad.org.tr/attachments/article/686/8.pdf)

Hofmannn, Paolo Saona (2011), "Determinants of the Profitability of the US Banking Industry", International Journal of Business and Social Science, 2(22), pp. 255-269. (http://ijbssnet.com/journals/Vol_2_No_22_December_2011/30.pdf)

İskenderoğlu, Ömer - Karadeniz, Erdinç- Atioğlu, Eyüp (2012), "Türk Bankacılık Sektöründe Büyüme, Büyüklük Ve Sermaye Yapısı Kararlarının Karlılığa Etkisinin Analizi". Eskişehir Osmangazi Üniversitesi İktisadi ve İdari Bilimler Dergisi, 7(1), ss. 291-311. (http://dergipark.gov.tr/oguiibf/issue/5717/76523)

Kabakçı, Yurdagül (2007), Sermaye Yapısının Firmaların Finansal Performansı Üzerine Etkisi. (Yayımlanmamış Doktora Tezi). Dokuz Eylül Üniversitesi, Sosyal Bilimler Enstitüsü.

Kabakçı, Yurdagül (2008, "Sermaye Yapısı ile İşletme Performansı Arasındaki İlişki: Gıda Sektöründe Bir Uygulama", Ege Akademik Bakış, 8(1), ss. 167-182. (http://www.onlinedergi.com/MakaleDosyalari/51/PDF2008_1_9.pdf)

Kaya, Yasemin Türker (2001), "Türk Bankacılık Sisteminde Net Faiz Marjının Modellenmesi", BDDK Mali Sektör Politikaları Dairesi Çalışma Raporları 2001/4. Ankara. 
Kaya, Yasemin Türker (2002), Türk Bankacılık Sektöründe Karlılığın Belirleyicileri 19972000. BDDK Mali Sektör Politikaları Dairesi Çalışma Raporları 2002/1. Ankara.

Korkmaz, Turhan - Y1ldı, Berk- Gökbulut, R. İlker (2010), "FVFM'nin İMKB Ulusal 100 Endeksindeki Geçerliliğinin Panel Veri Analizi İle Test Edilmesi", İstanbul Üniversitesi İşletme Fakültesi Dergisi, 39(1), ss. 95-105. (apbs.mersin.edu.tr/files/tkorkmaz/Publications_002.pdf)

Korkmaz, Özge - Karaca, Süleyman Serdar (2013, "Firma Performansını Etkileyen Faktörler ve Türkiye". Ege Akademik Bakış, 13(2), ss. 169-179. (http://www.onlinedergi.com/MakaleDosyalari/51/PDF2013_2_3.pdf)

Macit, Fatih (2012), "Bank Specific and Macroeconomic Determinants of Profitability: Evidence From Participation Banks in Turkey". Economics Bulletin, 32(1), ss. 586595. (https://ideas.repec.org/a/ebl/ecbull/eb-11-00769.html)

Pazarlığlu, M. Vedat - Gürler, Özlem Kiren (2007), "Telekomünikasyon Yatırımları ve Ekonomik Büyüme: Panel Veri Yaklaşımı". Finans Politik\& Ekonomik Yorumlar, 44(508), ss. $35-43$. (http://www.ekonomikyorumlar.com.tr/files/articles/152820004080_4.pdf)

Saeed, M. Muzaffar - Gull, A. Ali - Rasheed, M. Yasran (2013), "Impact of Capital Structure on Banking Performance (A Case Study of Pakistan)", Interdisciplinary Journal of Contemporary Research in Business, 4(10), pp. 393-403. (https://journalarchieves28.webs.com/393-403.pdf)

Samırkaş, Mustafa Can - Evci, Samet- Ergün, Bahadır (2014), "Türk Bankacılık Sektöründe Karlılı̆̆ın Belirleyicileri". KAU IIBF Dergisi, 5(8), 117-134. (http://dergipark.gov.tr/kauiibf/issue/19208/204227)

Şahin, Osman (2011), "Kobi'lerde Finansal Performansı Belirleyen Faktörler", ZKÜ Sosyal Bilimler Dergisi, 7(14), 183-200.( http://ijmeb.org/index.php/zkesbe/article/view/27)

Taşkın, F. Dilvin (2011), "Türkiye'de Ticari Bankaların Performansını Etkileyen Faktörler", $\begin{array}{llll}\text { Ege Akademik } & \text { Bakış, } & \text { 289-298. }\end{array}$ (http://www.onlinedergi.com/MakaleDosyalari/51/PDF2011_2_9.pdf)

Tatoğlu, Ferda Yerdelen (2012). Panel Veri Ekonometrisi. İstanbul: Beta.

Turgutlu, Evrim (2014), "Dynamics of Profitability in the Turkish Banking Industry", Ege Akademik Bakis, 14(1), 43. (http://www.onlinedergi.com/makaledosyalari/51/pdf2014_1_5.pdf)

Göçmen, Gamze - Demir, Yusuf - Bozdağ, Hakan (2013 ), "Küresel Mali Krizin Türk Bankacılık Sektörüne Etkileri: Yerli Ve Yabancı Bankaların İflas Riskleri Üzerine Karşılaştırmalı Bir Analiz", Dumlupınar Üniversitesi Sosyal Bilimler Dergisi EYİ Özel Sayıs1, 49-58. (http://dergipark.gov.tr/download/article-file/358532) 
Zeitun, Rami - Tian, Gary Gang (2007), "Capital Structure and Corporate Performance: Evidence From Jordan", Australasian Accounting Business \& Finance Journal, 1(4), 40-61. (doi:http://dx.doi.org/10.2139/ssrn.2496174) 
